\title{
Deep and Ultra-Deep Earthquakes Worldwide, Possible Anomalies in South America
}

\author{
M. Hagen" ${ }^{1}$ A. Azevedo ${ }^{2}$ \\ ${ }^{1}$ Universidade Federal Fluminense, Instituto de Fisica, Niteroi, RJ, Brazil (Retired); ${ }^{2}$ Faculdade de Ciências Aplicadas \\ da Unicamp-R. Pedro Zaccaria, Limeira, São Paulo
}

Correspondence to: M. Hagen, marhagen@indiana.edu; A. Azevedo, anibal.azevedo@fca.unicamp.br

Keywords: Deep Earthquakes (DQ), Ultra-Deep Earthquakes (UDQ), South America

Received: May 29, $2018 \quad$ Accepted: June 25, $2018 \quad$ Published: June 28, 2018

Copyright $\odot 2018$ by authors and Scientific Research Publishing Inc.

This work is licensed under the Creative Commons Attribution Isnternational License (CC BY 4.0).

http://creativecommons.org/licenses/by/4.0/

\section{(c) (i) Open Access}

\section{ABSTRACT}

The aim of this paper is to evaluate the worldwide variation of deep and ultra-deep earthquakes (DQ and UDQ) during the period 1996-2017. This project found only three locations around the globe presenting this kind of seismicity. Although there are other global settings showing deep seismicity, they are not periodical and cannot be considered by a statistical view. The three areas with intense activity for DQ and UDQ events are located mostly in subduction areas. The largest variations of DQ and UDQ border the Pacific Ocean and include the North Pacific, South Pacific, and South America. The major difference in this set is that the first two sites are subduction zones and the South American occurrences happened in the interior of the continent. Another anomaly is an internal layer between 300 $500 \mathrm{~km}$ in South America that shows no tremors in the period studied. However, below 500 $\mathrm{km}$ activity reappears, even at extreme depths of up to $650 \mathrm{~km}$. We suggested that the reason for those occurrences would be due to an anomaly in the asthenosphere in this region. This anomaly would probably be presenting a breakable material that was pushed by the Nazca platform against the South America plate. Other depths below $100 \mathrm{~km}$ in all the regions are discussed as well. We suggested that the reason for those occurrences was an anomaly created in the asthenosphere as part of the process of the South America collision with the Nazca plate. Part of the Nazca plate has subducted below South America, creating a slab as deep as $500 \mathrm{~km}$. The convergent slab is still moving against South America and sinking due to the gravity and rotation of the Earth. The discrepancies in the occurrences we tracked at different locations indicated that this slab had different thicknesses around South America. We found similar results for Vanuatu and Fiji; in these regions UDQ events occur at the subduction zones under the ocean with depths greater than $700 \mathrm{~km}$. Here, a possible explanation is that part of the lithosphere is subducted at these depths and is causing tremors. 


\section{INTRODUCTION}

The purpose of this study is to locate variation in the development of the deepest earthquakes worldwide. Most of these spots are in subduction zones around the Pacific Ocean. There are some other points with sporadic appearances of very deep earthquakes, but they do not happen with enough frequency to be included in the method established in this paper. This study is based on statistical approximations and numerical interactions between the data recorded, therefore, a small number of quakes in a few observed areas would not produce usable results.

There are five primary physical layers around the earth, namely the lithosphere, asthenosphere, mesosphere, outer core, and inner core. The lithosphere forms the uppermost layer of the Earth and comprises the crust and the upper mantle. It is commonly believed to be homogeneously distributed around the entire Earth, although this theory has not been proven. The lithosphere is divided into layers by depth, consisting of the crust and upper mantle portion of the earth. The asthenosphere is located at depths ranging from $200 \mathrm{~km}$ to $700 \mathrm{~km}$. During the period examined, several UDQ events were recorded in this range for multiple locations across the Earth. Current knowledge about the behavior of the earth's interior cannot adequately explain these UDQ events. We observed that the number of UDQ events at depths $\geq$ $500 \mathrm{~km}$ was relatively high. However, those earthquakes have scarcely been studied because they do not cause relevant damage to people and property. The aim of this study was to observe which locations showed an increase or decrease in DQ or UDQ events.

As in our previous studies, we will define regions where quakes occur at lower depths according to coordinate boundaries, described below [1-3]. These three regions are generally located at or near subduction zones. We also found occurrences in South America which were the only ultra-deep tremors inside a continental landmass. Other authors have previously studied South America for events near the coast, at the intersection of Pacific tectonic plates, but have examined DQ events only $[4,5]$. Those shallower earthquakes appear around the Nazca subduction zone at depths of $100-300 \mathrm{~km}$ [6-8], without any discussion of UDQs that occur intraplate within South America.

For this area situated within the coordinates $22.954 \mathrm{~N},-60.253 \mathrm{~S},-58.98 \mathrm{E},-140.273 \mathrm{~W}$, we propose the existence of a slab below $500 \mathrm{~km}$ in the asthenosphere that is part of the collision between the Nazca platform and the South America continent. The evolution of the data during the period examined suggests that the material is breakable around those depths and not malleable as is commonly attributed to the asthenosphere. Investigation of available records pointed to a layer with a thickness of $300-500 \mathrm{~km}$ (at the same coordinates) where there was no occurrence of tremors. We compared this area with other regions, including the North Pacific (comprising China, Japan, Philippines, Russia), and the South Pacific (which included Indonesia, Australia, Samoa, New Zealand, Fiji, Vanuatu). These regions consistently fit with the theory that UDQs happen at subduction zones. The exception in South America cannot be explained by common patterns.

\section{LOCATION OF EARTHQUAKESBY DEPTH}

To understand how the deepest earthquakes occur, this study concentrated on areas where events were recorded beneath $100 \mathrm{~km}$ in several different regions of the world. For most locations in the Northern Hemisphere, such as North America or Europe, there was no occurrence of UDQ events below 500 $\mathrm{km}$. The exceptions to this pattern are small spots in the Mediterranean Sea.

In the Northern Pacific region, UDQ events are generally on the Western side of the Ocean, stretching from Russia in the north to as far south as the Philippines.

In the Southern Pacific, UDQ events occurred regularly on both sides of the Ocean. However, on the eastern side they were located internal to the South America plate. This is the only location on the globe where earthquakes are occurring intraplate with depths of $500 \mathrm{~km}$ or more, as Figure 1 shows. Previous studies tried to establish the maximum depth reached by tremors around the world and concluded that these deepest tremors probably occurred around Fiji; researchers could not precisely determine focal depths below $700 \mathrm{~km}[9]$. 


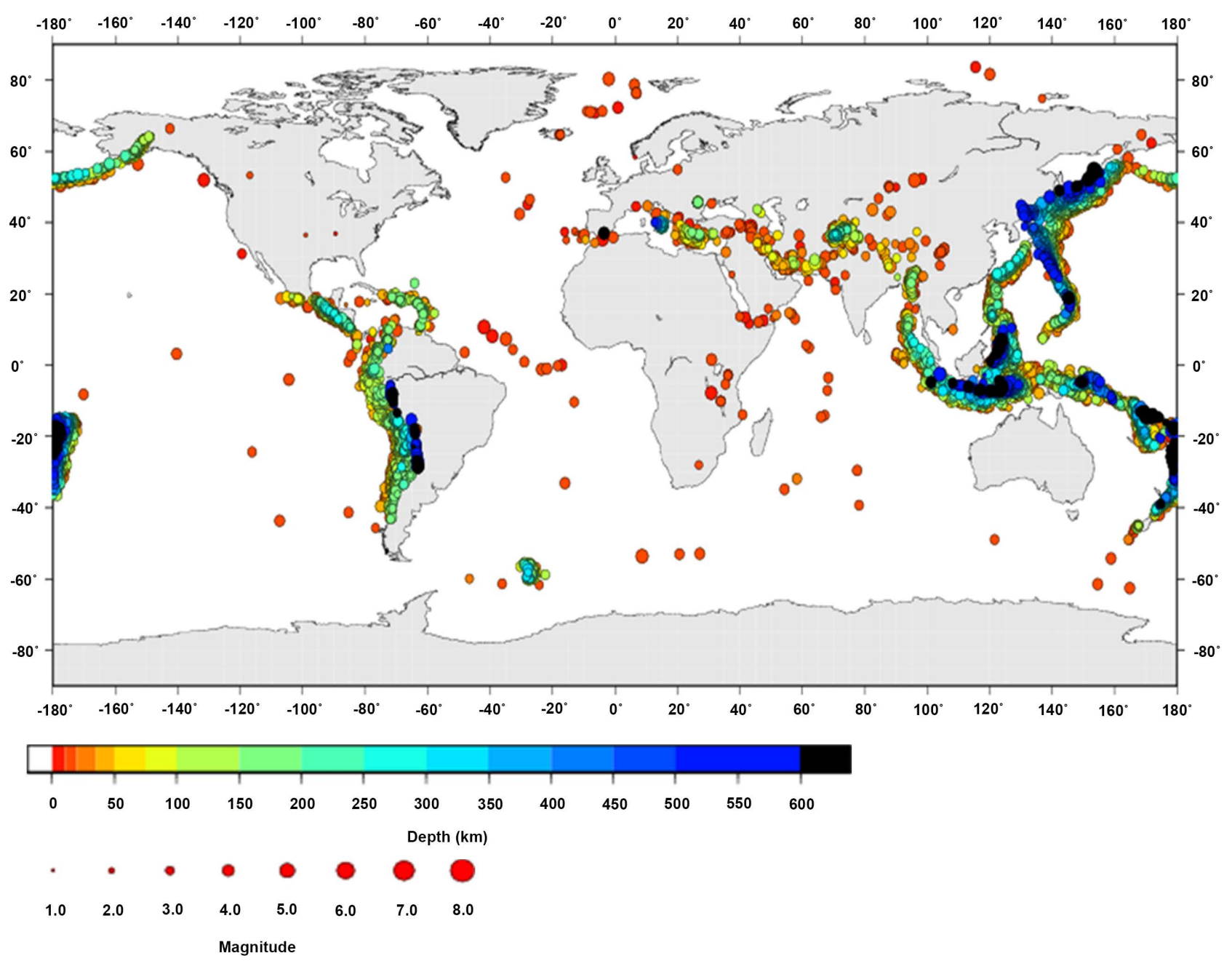

Figure 1. Worldwide earthquake distribution, showing the deepest earthquake locations. South America shows the only intraplate quakes with depth $>500 \mathrm{~km}$. The red dots represent the tectonic boundaries. (Data from http://www.ics.ac.uk/.)

The darkest blue dots in Figure 1 show the occurrence of the deepest depth quakes, concentrated in certain subduction zones worldwide. One exception is in the South America plate. It is impossible to make any observations about those occurrences without separating the regions by coordinates and the events by year. First, we took the following regions: North Pacific, South Pacific and South America, as defined by coordinates. We searched for tremors at depth ranges $100-200 \mathrm{~km}, 200-300 \mathrm{~km}, 300-400 \mathrm{~km}, 400-500$ $\mathrm{km}$, and below $500 \mathrm{~km}$. The period searched was 1996-2017, with additional data for South America that was analyzed since 1967. Due to the peculiar behavior of South America our data records sometimes considered earlier periods even though the records improved in reliability after 1980.

Other points worldwide display fewer documented events and will not be part of this analysis. They occurred at the Tyrrhenean Sea and Strait of Gibraltar, and only two events were recorded over the last twenty years. In the following sections we will divide the world regions according to locations of deep depth earthquakes and discuss the results found. Our data is obtained from several catalogs to detect earthquakes by depth and region [10-12].

\section{METHOD USED}

Our method to determine if earthquakes increase, decrease or remain constant in each region and 
depth is the following:

First, the regions with occurrences of earthquakes below $100 \mathrm{~km}$ are defined. We have 3 main regions, North Pacific (Alaska, Japan, Philippines, Russia), South Pacific (Australia, Fiji, Indonesia, Samoa, New Zealand) and South America. We examined quakes with minimum magnitude of M4.5 in the period 1996-2017, and divided quakes at depths below $100 \mathrm{~km}$ into five levels. The period of twenty-one years has been chosen before with differing reasoning. In this paper, longer periods are more statistically productive and may point to better results. We constructed tables of $\mathrm{N}$ values for each year searched and determined the average number of events per year by dividing the sum of all recorded events by 21 .

\subsection{Construction of Plots and Tables}

The data set comprises earthquakes recorded during the period 1996-2017. The sum of data values was $y_{1}=$ data recorded in the first-year level $n(100-200 \mathrm{~km}$, until $\geq 500 \mathrm{~km})$ in the region $\mathrm{X}(\mathrm{A}, \mathrm{B}, \mathrm{C})$

$$
\sum_{n 0}^{n n} Y n=y n 0+y n 1+\cdots y n n^{\prime},
$$

where $n=1996 \cdots 2017$, and $n^{\prime}$ is 21 years.

The mean is defined as

$$
\begin{gathered}
\text { Mean }=A=\frac{\sum_{n 0}^{n n} Y n}{19} \\
\text { Data value }- \text { mean }=Y n^{\prime}
\end{gathered}
$$

If $Y_{n}^{\prime}>A$, the value is higher than one during that year and it means the number of earthquakes exceeds the average. On the other hand, if $Y_{n}^{\prime}<A$ the number will be less than one during that year, indicating that the number of earthquakes was below the average. It is also possible to have a result of zero (though this was not common in our data set), which would mean there was no variation.

The next sections explain each region and discuss the earthquakes that occurred.

\subsection{Calculations on Earthquakes Depths $\geq 100 \mathrm{~km}$}

Calculating variance from annual averages will help to define and explain the locations where deep and ultra-deep quakes occur. Table 1 lists the boundary coordinates of each region studied.

\subsection{North Pacific Area (Alaska, Japan, Philippines, Russia)}

The North Pacific area is defined by the coordinates in Table 1 . To understand any variation or enhancement of the seismic activity, the magnitude events $M \geq 4.5$ were considered from the catalogs $[9,10]$. The depths were assigned layers corresponding to the ranges $100-200 \mathrm{~km}, 200-300 \mathrm{~km}, 300-400 \mathrm{~km}$, $400-500 \mathrm{~km}$, and $\geq 500 \mathrm{~km}$ as explained earlier. The period analyzed was 1996-2017. The calculated results for North Pacific area are displayed by Table A1 and Figure 2.

Figure 2 shows the average DQ variation in the period mentioned. The data reflects how the seismic activity increased, decreased, or was consistent from year to year.

Earthquakes at depths $\geq 100 \mathrm{~km}$ occurred at subduction zones, mostly along the Northern West Pacific coast. The Eastern Pacific coast at these latitudes showed no occurrences at the lowest depths, and in fact little activity $\geq 100 \mathrm{~km}$, including along the North American coast. At $200-300 \mathrm{~km}$, the frequency of tremors diminished in the Central Northern Pacific as well as the West Pacific coast. Below $300-400 \mathrm{~km}$, the number of events also decreased in the same area.

UDQ events $\geq 500 \mathrm{~km}$ are more frequent near the Sea of Okhotsk, a small area along the Chinese coast, and near Southern Japan around the Marianas islands. Overall, the number of tremors decreased with depth. However, the results of average events by depth presented the highest maximum to $\geq 500 \mathrm{~km}$ depth, as in 2010. Figure 3 shows how the events varied according to depth. Tremors at $100-200 \mathrm{~km}$ represent $61 \%$ of the total observed in the period, followed by the $200-300 \mathrm{~km}$ range with $17 \%$. Tremors 
Table 1. Locations and coordinates for earthquakes with depth $\geq 100 \mathrm{~km}$.

\begin{tabular}{cc}
\hline LOCATIONS & $\underline{\text { COORDINATES }}$ \\
\hline NORTH PACIFIC & $58.076 \mathrm{~N}, 0.70 \mathrm{~S},-132.891 \mathrm{E},-260.150 \mathrm{~W}$ \\
SOUTH PACIFIC: & $1.05513 \mathrm{~N},-49.611 \mathrm{~S},-132.891 \mathrm{E},-260.851 \mathrm{~W}$ \\
AUSTRALIA, INDONESIA, SAMOA & $22.594 \mathrm{~N},-60.253 \mathrm{~S},-55.898 \mathrm{E},-140.273 \mathrm{~W}$ \\
SOUTH AMERICA & \\
\hline
\end{tabular}

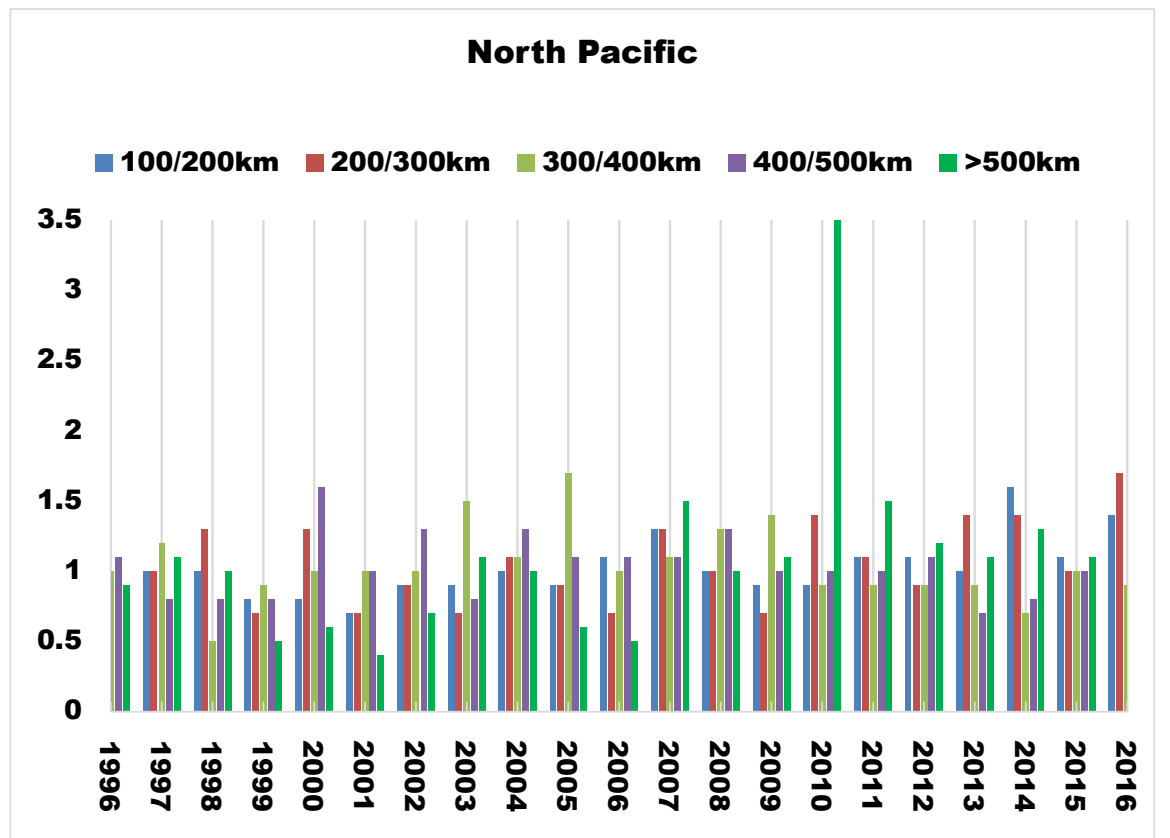

Figure 2. The variation of events by depth shows that the greatest enhancements occurred at depths $>500 \mathrm{~km}$.

of $\geq 500 \mathrm{~km}$ comprise only $4 \%$ of the total, but this lowest level is the depth with the most enhancements. Therefore, we concluded that quake occurrences in the North Pacific declined in this area as depth increased. Statistical comparison between the levels shows that $100-200 \mathrm{~km}$ was four times higher than the next greatest level; $200-300 \mathrm{~km}$ was five times lower than shallower depths, $300-400 \mathrm{~km}$ decayed nearly eight times relative to the shallower depths, and finally depths $\geq 500 \mathrm{~km}$ decayed fifteen times in relation to the shallowest level.

The quakes variation by depth can be estimated by the formula below:

$$
\text { quakes } \alpha 1 / \text { depth }
$$

The North Pacific region is the only worldwide area to verify this relationship.

\subsection{Southern Pacific (Australia, Indonesia, Fiji, Samoa, New Zealand)}

For this area the procedure adopted in the earlier section was applied, including the same period, magnitude and depth layers. The calculation was similar as well, and the results are displayed in Table A2 and Figure 4.

Table A2 for the South Pacific presents a similar scenario to the North Pacific; however, the depth with the highest maxima is $300-400 \mathrm{~km}$ (in 2008), and the same depth also shows the lowest minima in 2016. 


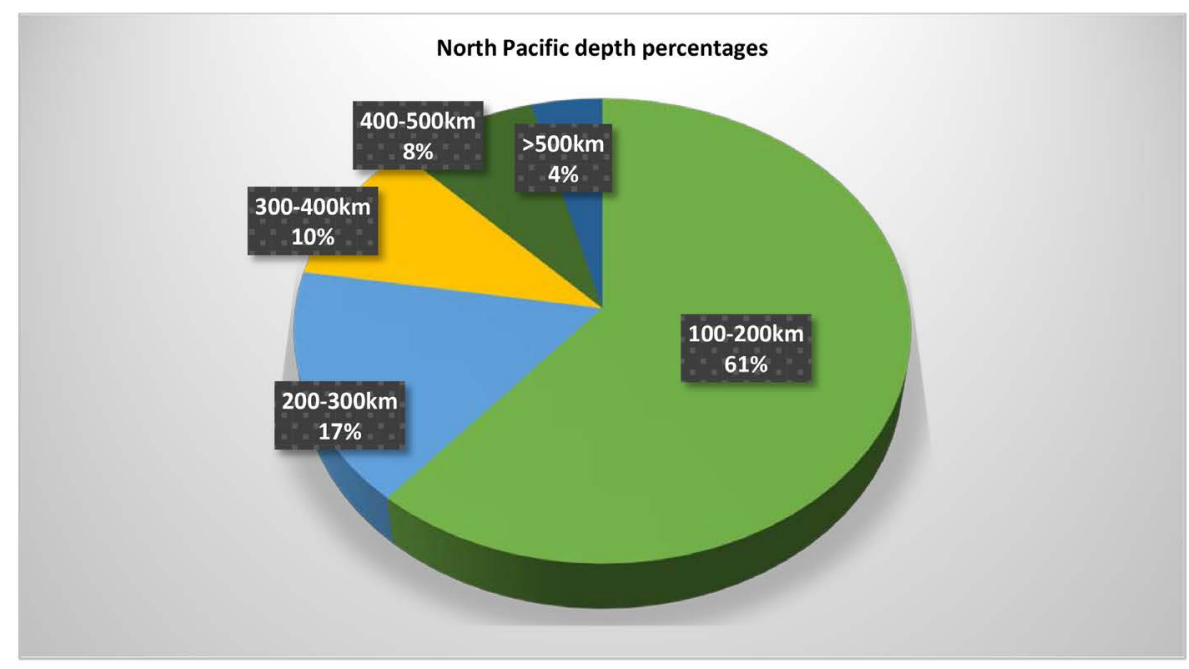

Figure 3. Shows the distribution of earthquakes by depth in the Northern Pacific. Occurrences of earthquakes decreased as depth increased.

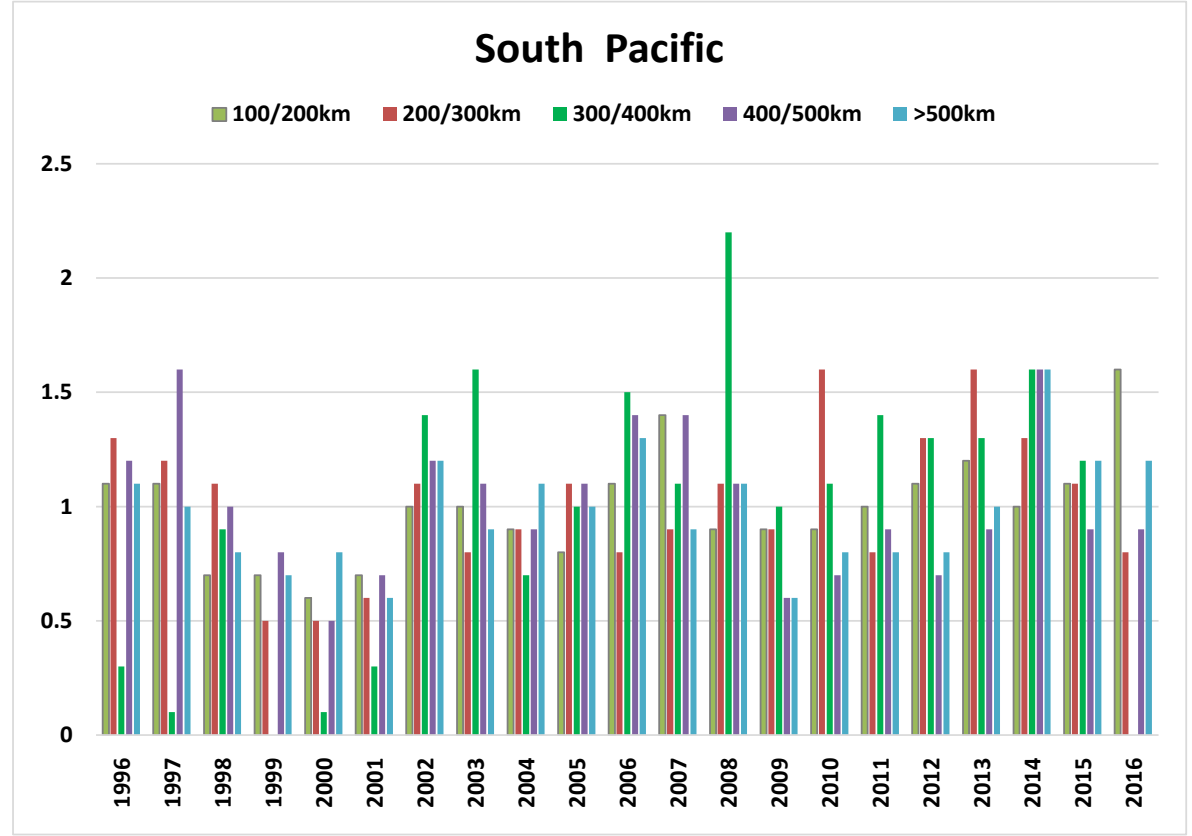

Figure 4. Australia, Indonesia, New Zealand, Samoa (South Pacific) and their seismic variation over twenty years. Observe the activity intensify below $300 \mathrm{~km}$, but also decay to zero in two years: 1999 and 2016.

Figure 5 shows the enhancement of quakes during the period, organized by depth. The $100-200 \mathrm{~km}$ range constitutes $64 \%$ of the total number of quakes, and the next three levels are lower in activity. Quakes increase again at the lowest level, $>500 \mathrm{~km}$. There is an enhancement of UDQ events that is more than twice as high as the $200-300 \mathrm{~km}$ range, ten times higher than the $300-400 \mathrm{~km}$ level, and five times higher than the $400-500 \mathrm{~km}$ depth. However, UDQ quake variation is three times lower than the $100-200 \mathrm{~km}$ range.

The interval that showed the biggest variation was at $>500 \mathrm{~km}$. In this area, UDQs occurred at $650 \mathrm{~km}$ depths around Fiji-Vanuatu. The deepest UDQ events found around the world was in the South Pacific in 


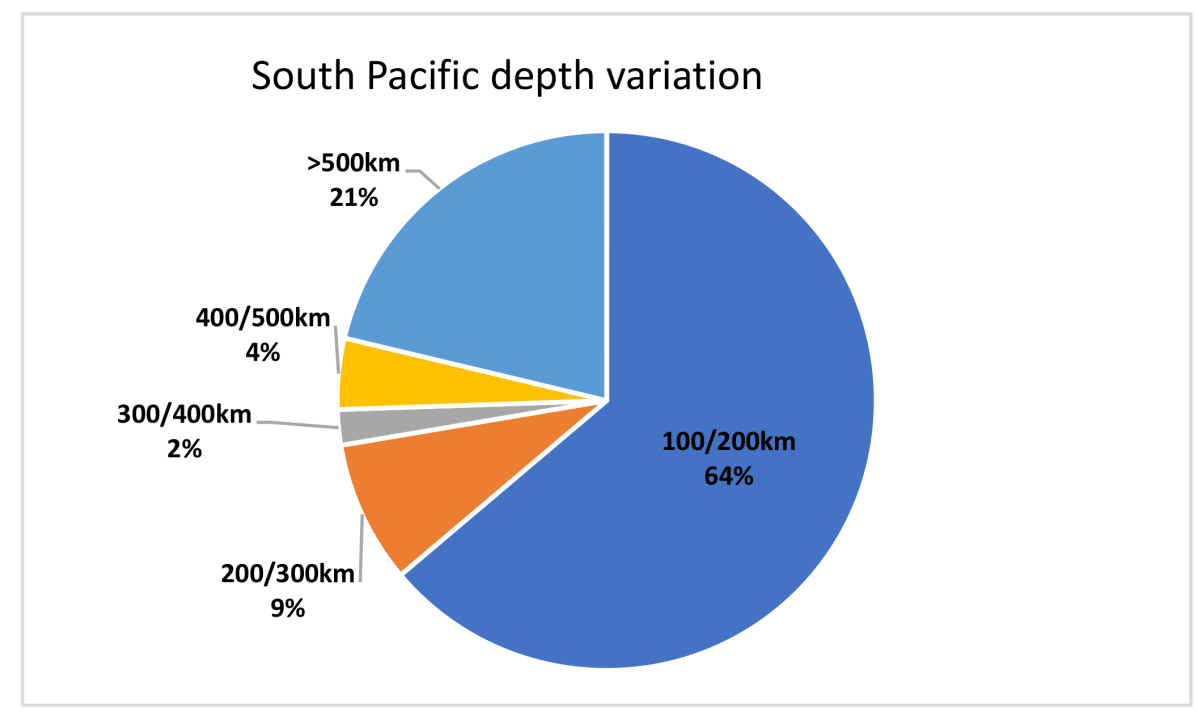

Figure 5. The percentage increase in the number of earthquakes is much higher in the $100-200 \mathrm{~km}$ range. Quakes at depths $\geq 500 \mathrm{~km}$ are also high compared to the middle depths. The results differ from the North Pacific.

the Fiji area; some of these quakes reached below $700 \mathrm{~km}$. The explanation for the UDQs in this region is that part of the lithosphere sank into an environment where the tectonics were not brittle as the asthenosphere. However, the lithospheric material was weak and fragile, and gravitational forces toward the center of the Earth triggered the UDQs. This region in question is situated between Fiji and Tonga, and the events intensify after 2004 with quakes at depths as low as $720 \mathrm{~km}$. The results from the North Pacific compared with the South Pacific indicate that there is an internal factor in the Earth that increases seismological activity in the South Pacific but not the North Pacific.

\subsection{South America Region}

The last zone examined has unique characteristics not found in the other two. The coordinates delimited an area with only three lower depths that were seismologically active; the $300-500 \mathrm{~km}$ layer offered insufficient tremors for statistical purposes. Table A3 displays values for each year comparing each year's events to the average. We observed an increase of events between 2005-2017 with one exception in 2009 for DQ at $100-200 \mathrm{~km}$. For $200-300 \mathrm{~km}$, DQ events were below or equal to the average over 10 years. At depths $300-500 \mathrm{~km}$ there were no statistically relevant tremors. For UDQ events, eight years registered several events equal to or below the average, and the remaining years presented increases, with three exceptional variations in 2005, 2011, and 2016. Shallower earthquakes in the $100-300 \mathrm{~km}$ range appear near the Pacific coast or in the region where the subducting portion of the Nazca plate is assumed to be located. Below $500 \mathrm{~km}$, the events occurintraplate in the middle of the continent. This is the only worldwide area where such events occur. It is an unexpected result for $\geq 500 \mathrm{~km}$ depth in a layer that is supposed to belong to the asthenosphere. The annual variation of those events is shown in Figure 6.

Observe the years when the number of events compared to the average was zero. Figure 7 displays the proportional variation for quakes by depth. $87 \%$ of tremors are at the shallowest depths, $100-200 \mathrm{~km}$; $11 \%$ are located at $200-300 \mathrm{~km}$; and the remaining $2 \%$ of quakes fall below $500 \mathrm{~km}$. These proportions need to be examined with Table A3 and Figure 6 to understand the discrepancies for each depth.

Figure 8 shows the northernmost events located at $5.57 \mathrm{~S}, 71.88 \mathrm{~W}$ at Amazonas, Brazil. There is a long corridor of activity between this position and Santiago del Estero, where the last tremors at this depth are observed. On the other hand, farther south there are gaps without any occurrence of quakes, mostly between Madre de Dios (Peru) and Northern La Paz (Bolivia). 


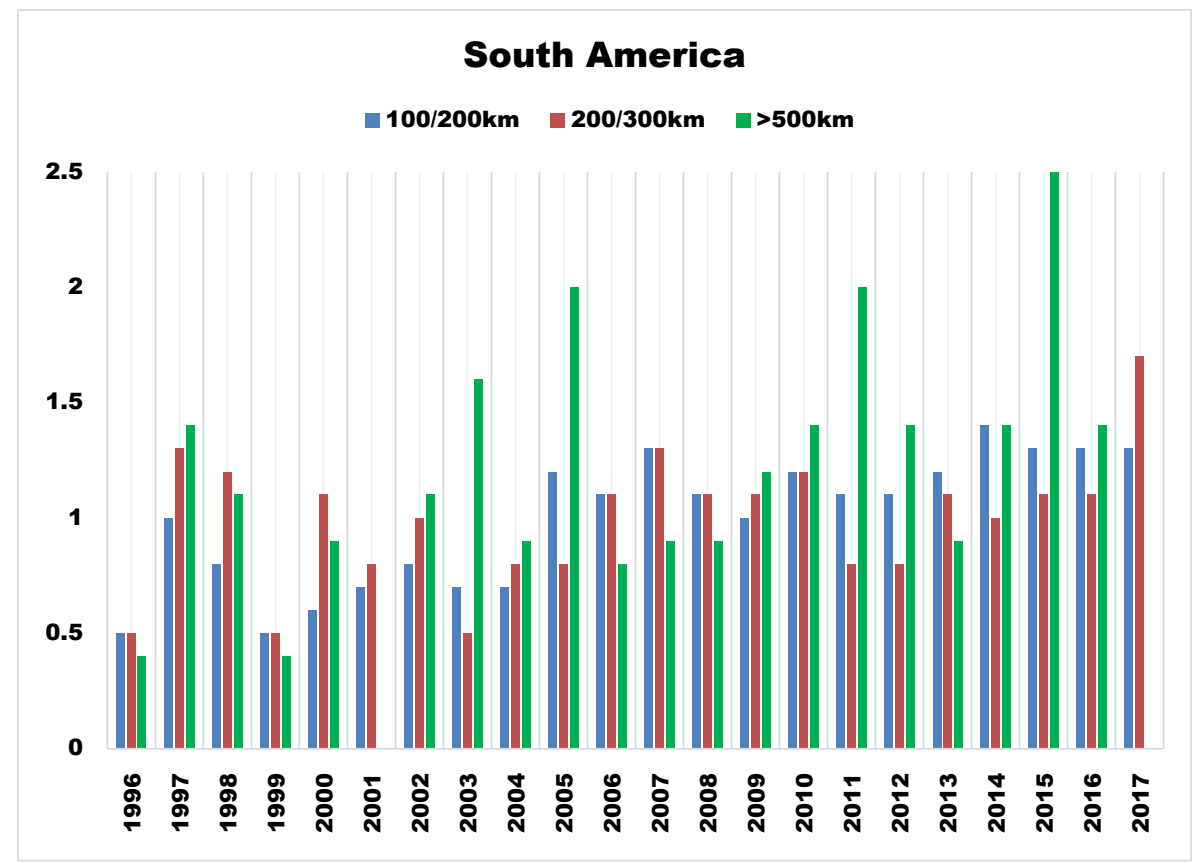

Figure 6. Earthquake variation values for South America, divided by depths $>100 \mathrm{~km}$. Intraplate tremors $>500 \mathrm{~km}$ are also included.

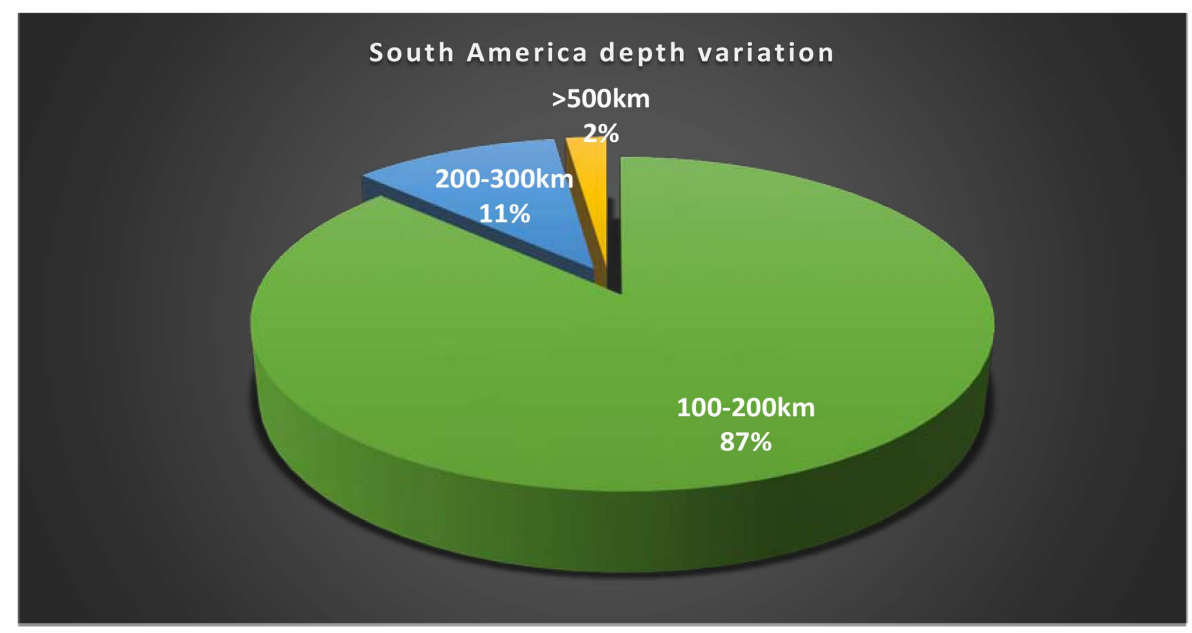

Figure 7. South America variation by depth. Layers showing zero variation from the average are excluded.

Figure 9 shows the gaps without UDQ events to the south of the area shown in Figure 8.

The next image, Figure 10, shows where the southernmost UDQ events appeared around Santiago del Estero, Argentina. at location 28.814 S, 62.855 W.

The last result for South America is illustrated in Figure 11 with the deepest UDQ events recorded below $650 \mathrm{~km}$. The figure shows the furthest north location near the Peru-Brazil border and the southernmost in La Paz, Bolivia. There are no deeper quakes, and these deepest tremors are confined to the area shown. Depth of quakes are marked in the figure; the deepest quake between 1980 and 2018 was 674 $\mathrm{km}$. pendix $\mathrm{A}$.

The tables constructed for the activity in all three worldwide regions researched are displayed in Ap- 


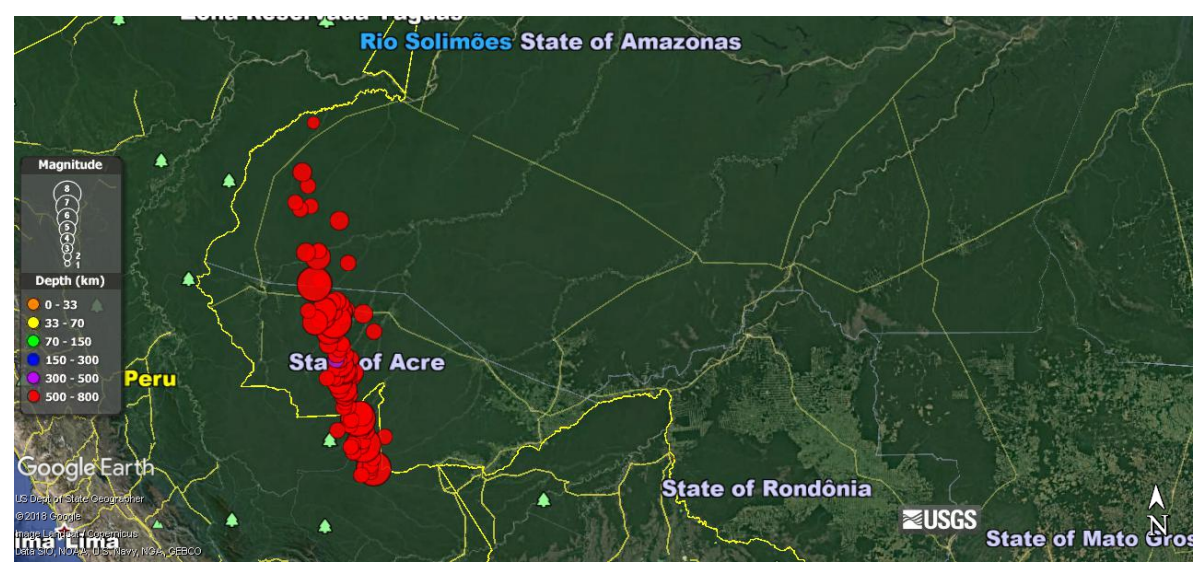

Figure 8. Thered dots represent the northern cluster of ultra-deep earthquakes in South America between 1980 and 2018. They are intraplate with depth $\geq 500 \mathrm{~km}$, and magnitude $>2.5$.

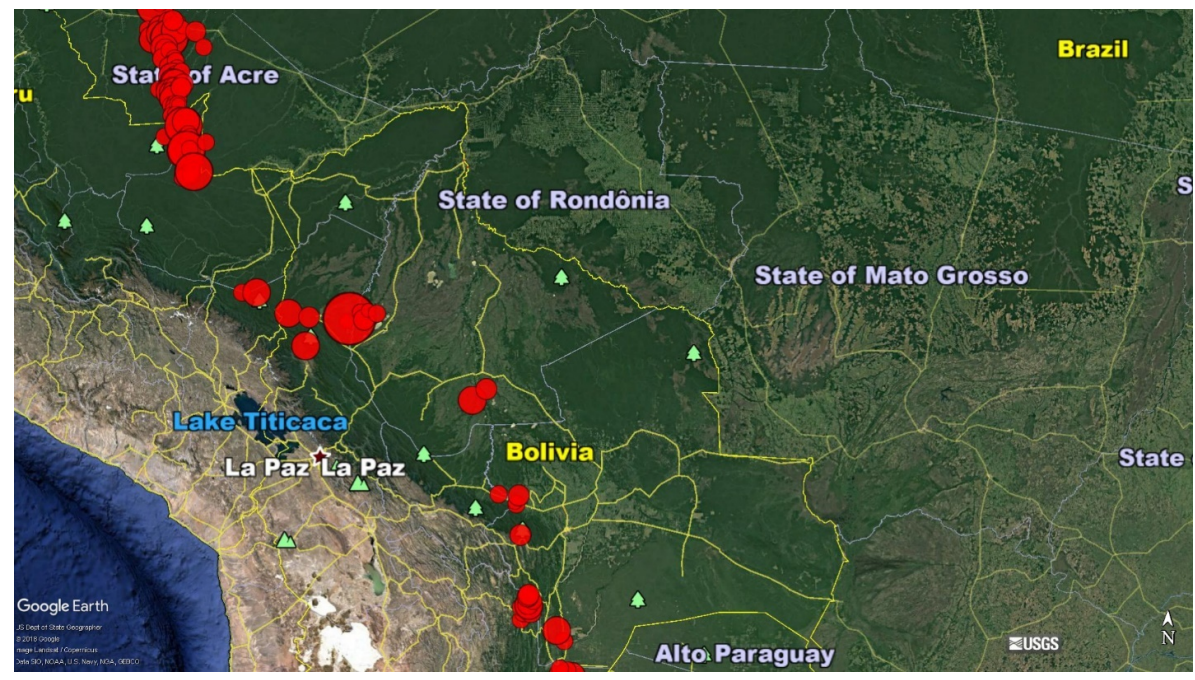

Figure 9. Gaps in the South America map, showing locations without UDQ occurrences in the entire period searched.

\section{RESULTS EXPLANATION}

The worldwide investigation for earthquakes with depths below $100 \mathrm{~km}$ showed that they generally occurred throughout the Pacific. A small number of occurrences were reported in other locations, such as Afghanistan or near Europe in the Atlantic Ocean. Atlantic Ocean deep events are rare, happening only two times in the Caribbean during the range 1996-2017. The Pacific Ocean is the location of most UDQ events $\geq 500 \mathrm{~km}$ This paper did not discuss the situation encountered in the Thyrreanean Sea and Strait of Gibraltar, where several tremors occurred below $100 \mathrm{~km}$, even including a few ultra-deep events in the period 1996-2017. The number of events for these locations in the time range studied is much lower and impossible to find a statistical correlation.

South America presented a lack of tremors between $300-500 \mathrm{~km}$ in the coordinate range chosen. This is a noteworthy gap considering the overall activity level of the region. UDQ events also are not localized at subduction regions as in the Pacific. Overall, the North Pacific showed enhancement of events at shallower depths, and decreasing enhancement as depth increases. The South Pacific behaved in the opposite manner. 


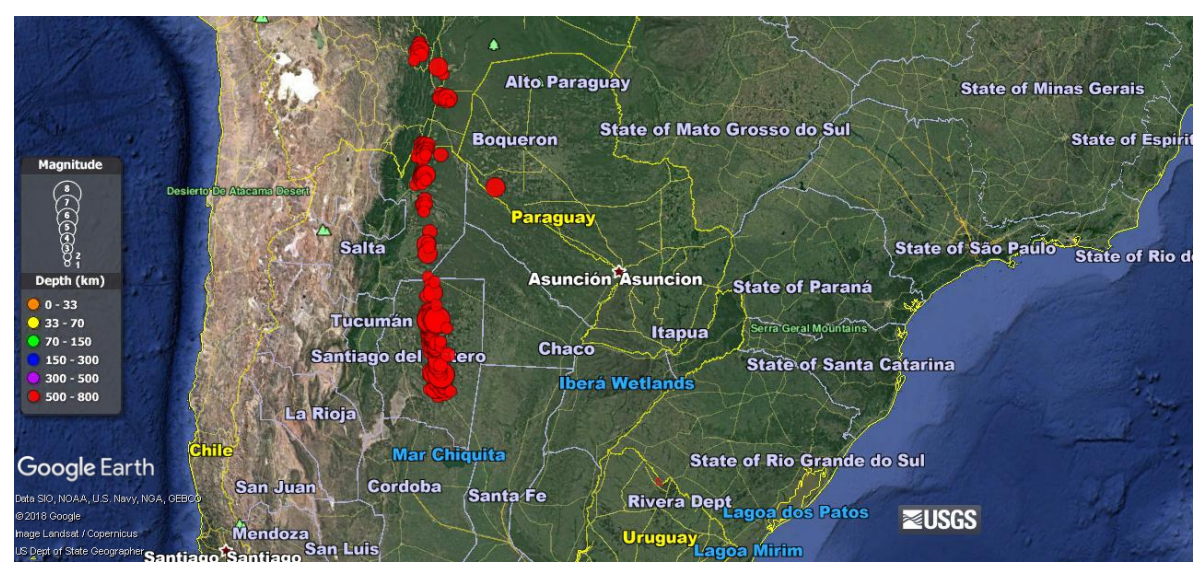

Figure 10. The Southernmost UDQ locations South America. Occurrences stop near Mar Chiquita.

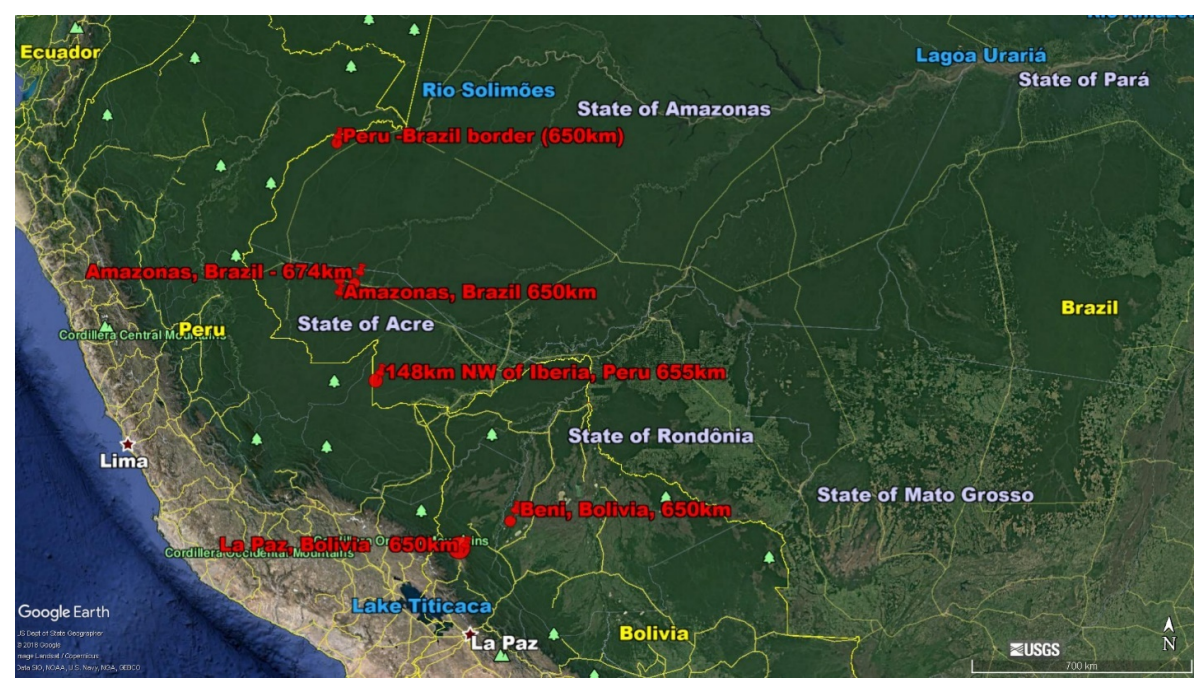

Figure 11. Deepest quakes, with depths marked, in South America over the last 40 years, distributed between Amazonas, Brazil in the North and La Paz, Bolivia in the South.

We suggest that the unusual and localized discrepancy in South America is caused by movement of the Nazca plate that research does not fully understand yet. The area of deepest quakes is relative distant from the subduction zone, but we know that the Nazca plate displaces eastward at 15 to $17 \mathrm{~cm} /$ year and the South American continent moves westward at $10 \mathrm{~cm} /$ year. The contrary movements cause shallower earthquakes along South America's western coast, but we suggest that already-subducted portions of the Nazca plate may be causing the UDQ events farther within the continent. The abnormal characteristics observed in South America suggest an anomaly in the crust below the continent at depths $\geq 500 \mathrm{~km}$. The explanation for this anomaly is that the Nazca plate is constructed of two slabs that we call the superior slab (SS) and inferior slab (IS). At the collision of the South American and Nazca Plates, the upper plate (SS) sinks into the subduction area, and part of the IS strikes the continent at extreme depth of around 500 $\mathrm{km}$. The top plate causes shallower earthquakes between $100-300 \mathrm{~km}$. The lower plate (IS) triggers earthquakes below $500 \mathrm{~km}$, but there is a gap between $300-500 \mathrm{~km}$ with less brittle material that did not generate any kind of earthquake. The tremors observed below $500 \mathrm{~km}$ are created due to the continuous movement of this lower plate (IS) eastward underneath the South American continent. It is also possible 
the lower plate is heavier, brittle with a different composition from the upper plate, and this will deepen the tremors made possible by the gravitational force acting on the plate.The pattern of UDQ events in the South American continent may also suggest the shape of this subducted plate; the line of activity stretching from the state of Acre's Northern/Colombian border to the south of Bolivia may indicate the boundaries of the plate that sank below the continental plate long ago.

The quakes in the north part of South America happen below $650 \mathrm{~km}$. The search for earthquakes over a longer period, 1980-2018, showed that the oldest occurred in 1987 in the Acre region; this was also the deepest event at $674 \mathrm{~km}$. The farthest southwest events were in Bolivia, with two occurrences at 650 $\mathrm{km}$. Our conclusion from this pattern of UDQ in South America is that the deepest slab (IS) is uneven; this also indicates that the IS thickness varies by location. The location of events may establish the boundaries and dimensions of the inferior slab in relation to the South American continent, and by this logic the southernmost point of the IS would be in Argentina as shown last section.

\section{GENERAL CONSIDERATIONS}

The first part of this paper worked with earthquakes at depths $\geq 100 \mathrm{~km}$, divided into the most important locations where those events occurred. Our results pointed out that the biggest dissimilarities, enhancements or decays were located below $300 \mathrm{~km}$ at subduction zones. An exception was found in South America with the occurrences of intraplate tremors with depths $\geq 500 \mathrm{~km}$. There is a depth layer $300-500$ $\mathrm{km}$ without any occurrences of tremors. This suggests that at this level, the location is probably less brittle than the layers above. Below $500 \mathrm{~km}$ the tremors start to rise again inside the continent, which points to a brittle area that has no explanation so far. This region is also an exception compared with the other regions presenting DQ and UDQ events at all levels recorded in our data catalogs [10-12].

Our calculations showed a majority of DQ and UDQ events are located in the Pacific Ring of Fire. In the North Pacific, it is possible to generalize the relationship "1/depth $\alpha \mathrm{n}^{\circ}$ of quakes"; therefore, greater depth leads to fewer quakes. In the South Pacific, we see a similar configuration up to $500 \mathrm{~km}$, with an increase in quakes at depths $\geq 500 \mathrm{~km}$. Other UDQ events in the Southern Pacific present similarbehavior to shallower quakes atcertain coordinates, and follow similar trajectories. However, most of them occurred in the ocean and demand more investigation into the locations of the epicenters.

\section{CONCLUSION}

This study described certain characteristics for DQ and UDQ events across three main regions, most of them around the Pacific Ring of Fire, with the exception of UDQ events within the continent of South America. We proposed that South America has a lithospheric slab buried in the region with an approximate depth between $500-670 \mathrm{~km}$. The thickness of this slab varies, and it appears to disappear suddenly in southern Argentina. The South Pacific showed similar characteristics, but at a subduction zone near Fiji with depths ranging from $500 \mathrm{~km}$ to $730 \mathrm{~km}$. In our next paper, we will continue to examine features and external influences for events occurring at the specific locations discussed here.

\section{ACKNOWLEDGEMENTS}

I would like to thank my former collaborator and director of DTU, Prof. Eigil Friis-Christensen, Denmark, Paul Lindell, for editing and corrections on this paper.

\section{REFERENCES}

1. Hagen, M. and Azevedo, A. (2017) Possible Connections between X-Solar Flares and Worldwide Variations in Seismicity Enhancement. Natural Science, 9, Article ID: 81481.

2. Hagen, M. and Azevedo, A. (2017) Sun-Moon-Earth Interactions, External Factors for Earthquakes. Natural Science, 9, Article ID: 77298.

3. Hagen, M. and Azevedo, A. (2016) Gravitational Moon-Earth Forces, Triggering Earthquakes in Subduction 
Zones. Journal of Geography, Environment and Earth Sciences International, 8, 1-14.

4. Alvarez, O., Gimenez, M., Folguera, A., Spagnoto, S., Bustos, E., Baez, W. and Braitenberg, C. (2015) New Evidence about the Subduction of the Copiapó Ridge beneath South America, and Its Connection with the Chilean-Pampean Flat Slab, Tracked by Satellite GOCE and EGM2008 Models. Journal of Geodynamics, 91, 65-88. https://doi.org/10.1016/j.jog.2015.08.002

5. Assumpção, M., Dias, F.L., Zevallos, I. and Naliboff, J.B. (2016) Intraplate Stress Field in South America from Earthquake Focal Mechanisms. Journalof South American Earth Sciences, 71, 278-295. https://doi.org/10.1016/j.jsames.2016.07.005

6. Heintz, M., Debayle, E. and Vauch, A. (2005) Upper Mantle Structure of the South American Continent and Neighboring Oceans from Surface Wave Tomography. Tectonophysics, 406, 115-139. https://doi.org/10.1016/j.tecto.2005.05.006

7. Almeida, F.F.M., Neves, B.B.B. and Carneiro, C. (2000) The Origin and Evolution of the South American Platform. Earth-Science Reviews, 50, 77-111. https://doi.org/10.1016/S0012-8252(99)00072-0

8. Klotza, J., Khazaradzea, G., Angermanna, D., Reigbera, C., Perdomob, R. and Cifuente, O. (2001) Earthquake Cycle Dominates Contemporary Crustal Deformation in Central and Southern Andes. Earth and Planetary Science Letters, 193, 437-446. https://doi.org/10.1016/S0012-821X(01)00532-5

9. Oliver, J. and Isacks, B. (1967) Deep Earthquake Zones, Anomalous Structures in the Upper Mantle, and the Lithosphere. Journal of Geophysical Research, 72, 4259-4275.

10. https://earthquake.usgs.gov/earthquakes/search/

11. http://ds.iris.edu/wilber3/find_event

12. https://www.emsc-csem.org/Earthquake/?filter=yes 


\section{APPENDIX A}

Table A1. Yearly variation in events in the Northern Pacific, divided by depth.

\begin{tabular}{cccccc}
\hline \multicolumn{7}{c}{ North Pacific } & & \\
\hline Year & $100 / 200 \mathrm{~km}$ & $200 / 300 \mathrm{~km}$ & $300 / 400 \mathrm{~km}$ & $400 / 500 \mathrm{~km}$ & $>500 \mathrm{~km}$ \\
\hline 1996 & 0.6 & 0.7 & 1 & 1.1 & 0.9 \\
1997 & 1 & 1 & 1.2 & 0.8 & 1.1 \\
1998 & 1 & 1.3 & 0.5 & 0.8 & 1 \\
1999 & 0.8 & 0.7 & 0.9 & 0.8 & 0.5 \\
2000 & 0.8 & 1.3 & 1 & 1.6 & 0.6 \\
2001 & 0.7 & 0.7 & 1 & 1 & 0.4 \\
2002 & 0.9 & 0.9 & 1 & 1.3 & 0.7 \\
2003 & 0.9 & 0.7 & 1.5 & 0.8 & 1.1 \\
2004 & 1 & 1.1 & 1.1 & 1.3 & 1 \\
2005 & 0.9 & 0.9 & 1.7 & 1.1 & 0.6 \\
2006 & 1.1 & 0.7 & 1 & 1.1 & 0.5 \\
2007 & 1.3 & 1.3 & 1.1 & 1.1 & 1.5 \\
2008 & 1 & 1 & 1.3 & 1.3 & 1 \\
2009 & 0.9 & 0.7 & 1.4 & 1 & 1.1 \\
2010 & 0.9 & 1.4 & 0.9 & 1 & 3.5 \\
2011 & 1.1 & 1.1 & 0.9 & 1 & 1.5 \\
2012 & 1.1 & 0.9 & 0.9 & 1.1 & 1.2 \\
2013 & 1 & 1.4 & 0.9 & 0.7 & 1.1 \\
2014 & 1.6 & 1.4 & 0.7 & 0.8 & 1.3 \\
2015 & 1.1 & 1 & 1 & 0.8 & 0.4 \\
2016 & 1.4 & 1.7 & 0.9 & 1 & \\
\hline
\end{tabular}


Table A2. Yearly variation in events in the Southern Pacific, divided by depth.

\begin{tabular}{cccccc}
\hline \multicolumn{7}{c}{ Australia, Indonesia, Fiji, Samoa, New Zealand } \\
\hline Year & $100 / 200 \mathrm{~km}$ & $200 / 300 \mathrm{~km}$ & $300 / 400 \mathrm{~km}$ & $400 / 500 \mathrm{~km}$ & $>500 \mathrm{~km}$ \\
\hline 1996 & 1.1 & 1.3 & 0.3 & 1.2 & 1.1 \\
1997 & 1.1 & 1.2 & 0.1 & 1.6 & 1 \\
1998 & 0.7 & 1.1 & 0.9 & 1 & 0.8 \\
1999 & 0.7 & 0.5 & 0 & 0.8 & 0.7 \\
2000 & 0.6 & 0.5 & 0.1 & 0.5 & 0.8 \\
2001 & 0.7 & 0.6 & 0.3 & 0.7 & 0.6 \\
2002 & 1 & 1.1 & 1.4 & 1.2 & 1.2 \\
2003 & 1 & 0.8 & 1.6 & 1.1 & 0.9 \\
2004 & 0.9 & 0.9 & 0.7 & 0.9 & 1.1 \\
2005 & 0.8 & 1.1 & 1 & 1.1 & 1 \\
2006 & 1.1 & 0.8 & 1.5 & 1.4 & 1.3 \\
2007 & 1.4 & 0.9 & 1.1 & 1.4 & 0.9 \\
2008 & 0.9 & 1.1 & 2.2 & 1.1 & 1.1 \\
2009 & 0.9 & 0.9 & 1 & 0.6 & 0.6 \\
2010 & 0.9 & 1.6 & 1.1 & 0.7 & 0.8 \\
2011 & 1 & 0.8 & 1.4 & 0.9 & 0.8 \\
2012 & 1.1 & 1.3 & 1.3 & 0.7 & 0.8 \\
2013 & 1.2 & 1.6 & 1.3 & 0.9 & 1.2 \\
2014 & 1 & 1.3 & 1.6 & 1.6 & 0.9 \\
2015 & 1.1 & 1.1 & 1.2 & 0.9 & \\
2016 & 1.6 & 0.8 & 0 & & 1.9 \\
\hline
\end{tabular}


Table A3. Yearly variation in events in South America, divided by depth.

\begin{tabular}{|c|c|c|c|c|}
\hline \multicolumn{2}{|c|}{ South America } & \multirow[b]{2}{*}{$200 / 300 \mathrm{~km}$} & \multirow[b]{2}{*}{$300 / 500 \mathrm{~km}$} & \multirow[b]{2}{*}{$>500 \mathrm{~km}$} \\
\hline Year & $100 / 200 \mathrm{~km}$ & & & \\
\hline 1996 & 0.5 & 0.5 & & 0.4 \\
\hline 1997 & 1 & 1.3 & & 1.4 \\
\hline 1998 & 0.8 & 1.2 & & 1.1 \\
\hline 1999 & 0.5 & 0.5 & & 0.4 \\
\hline 2000 & 0.6 & 1.1 & & 0.9 \\
\hline 2001 & 0.7 & 0.8 & & 0 \\
\hline 2002 & 0.8 & 1 & & 1.1 \\
\hline 2003 & 0.7 & 0.5 & & 1.6 \\
\hline 2004 & 0.7 & 0.8 & & 0.9 \\
\hline 2005 & 1.2 & 0.8 & & 2 \\
\hline 2006 & 1.1 & 1.1 & & 0.8 \\
\hline 2007 & 1.3 & 1.3 & & 0.9 \\
\hline 2008 & 1.1 & 1.1 & & 0.9 \\
\hline 2009 & 1 & 1.1 & & 1.2 \\
\hline 2010 & 1.2 & 1.2 & & 1.4 \\
\hline 2011 & 1.1 & 0.8 & & 2 \\
\hline 2012 & 1.1 & 0.8 & & 1.4 \\
\hline 2013 & 1.2 & 1.1 & & 0.9 \\
\hline 2014 & 1.4 & 1 & & 1.4 \\
\hline 2015 & 1.3 & 1.1 & & 2.6 \\
\hline 2016 & 1.3 & 1.1 & & 1.4 \\
\hline 2017 & 1.3 & 1.7 & & 0 \\
\hline
\end{tabular}

